\title{
Surgical Outcome of Spinal Tumour: Our Experience in Dhaka Medical College \& Hospital
}

\author{
Das $\mathrm{S}^{1}$, Zahan $\mathrm{KFI}^{2}$, Rashid $\mathrm{MM}^{3}$, Sarkar $\mathrm{AC}^{4}$, Khan $\mathrm{SI}^{5}$, Ashfaq $\mathbf{M}^{6}$, Mahbub $\mathrm{H}^{7}$, Islam $\mathrm{R}^{8}$, \\ Islam $\mathrm{MM}^{9}$, Khan $\mathrm{SI}^{10}$, Chowdhury $\mathrm{D}^{11}$.
}

\begin{abstract}
:
Introduction: Surgical outcome of spinal tumour varies depending on a number of factors such as: site of tumour, compression within the spinal canal, the histological characteristics of tumour, the neurological progression and initial response to corticosteroid therapy, patient's age, comorbidity, tumour extension, involvement of neighboring structures and organs etc.

Materials \& Methods: The 86 patients with spinal tumour underwent surgery by our team in 7 years (2011-2018) were reviewed retrospectively.

Discussion: Analysis of the surgical outcome of our spinal tumour patients was done on different variables like age, sex, presenting symptoms, neuroimaging, comorbidities etc. The aim of surgery was decompression of the spinal cord, total removal of the tumour when possible and spinal stabilization when needed. Out of our 86 patients with spinal tumour, extradural tumour comprises 18, intradural tumour 56 and intramedullary tumour 12.

Conclusion: The aim of this study is to analyze the data to made conclusion for more effective strategy as per site, size, type, resectibility and histological variety to establish and effective treatment protocol and prevention of per-operative and post-operative complications. Intradural extramedullary tumour can be radically resected with no mortality and minimal peri-operative morbidity. But resection of intramedullary spinal tumour is difficult, hazardous and usually incomplete, so needs much more skilled and meticulous surgical hands.
\end{abstract}

Key Words: Spinal tumours, spinal cord compression, surgical outcome, intramedullay, extramedullary.

Bang. J Neurosurgery 2019; 8(2): 63-67

1. Dr. Sukriti Das, Associate Professor, Department of Neurosurgery, Dhaka Medical College \& Hospital, Dhaka.

2. Dr. Kanij Fatema Ishrat Zahan, Assistant Professor,Department of Neurosurgery,Dhaka Medical College \& Hospital, Dhaka.

3. Dr. Md. Mamunur Rashid, Resident, Phase-B, Department of Neurosurgery, Dhaka Medical College \& Hospital, Dhaka.

4. Dr. Asit Chandra Sarkar, Professor, Department of Neurosurgery, Dhaka Medical College \& Hospital, Dhaka.

5. Dr. Shamsul Islam Khan, Medical Officer, Department of Neurosurgery, Dhaka Medical College \& Hospital, Dhaka.

6. Dr. Musannah Ashfaq, Resident, Phase-B, Department of Neurosurgery, Dhaka Medical College \& Hospital, Dhaka.

7. Dr. Hasan Mahbub, Resident, Phase-B, Department of Neurosurgery, Dhaka Medical College \& Hospital, Dhaka.

8. Dr. Rakibul Islam, Resident, Phase-B, Department of Neurosurgery, Dhaka Medical College \& Hospital, Dhaka.

9. Dr. Md. Moidul Islam, Resident, Department of Neurosurgery, Dhaka Medical College \& Hospital, Dhaka.

10. Dr. Shahriar Islam Khan, Resident, Department of Neurosurgery, Dhaka Medical College \& Hospital, Dhaka.

11. Dr. Dhiman Chowdhury, Associate Professor, Department of Neurosurgery, Bangabandhu Sheikh Mujib Medical University, Dhaka.

Address of Correspondence: Dr. Sukriti Das, Associate Professor, Department of Neurosurgery, Dhaka Medical College \& Hospital, Dhaka. Cell phone: +8801711676848, e-mail: sukriti66@yahoo.com

\section{Introduction:}

Surgical outcome of spinal tumours varies depending on a number of factors such as: site of tumour, compression within the spinal canal, the histological characteristics of tumour, the neurological progression and initial response to corticosteroid therapy, patient's age, comorbidity, tumour extension, involvement of neighboring structures and organs etc. Treatment of spine and spinal cord tumour is complex and a multidisciplinary approach is required ${ }^{1}$. Treatment options are surgery, radiation therapy and chemotherapy ${ }^{2}$. This study was conducted to analyze factors with impact on the functional outcome in a series of 86 surgically treated patients with spinal tumour and to point out the characteristics of the different histological entities.

The signs and symptoms of intradural extramedullary tumour are not specific to tumours and are similar to those caused by any spinal disorder that produces symptoms of spinal cord or nerve root compression. Because of the slow growth of these tumours, symptoms may be subtle and progress slowly over 
time before diagnosis ${ }^{3}$. The benign nature of ordinary spinal schwannomas is well documented ${ }^{4-7}$. Total surgical removal can usually be achieved and shortterm outcome is favorable in those who are not too severely crippled before operation 5,7 .

Intradural-extramedullary (ID-EM) tumours are the most commonly observed intradural spinal tumours, comprising over $60 \%$ of tumours found within the spinal canal ${ }^{8}$. While consisting of a heterogeneous group of pathological entities, the vast majority of these lesions are one of three types: meningiomas, schwannoma or neurofibroma? ${ }^{9}$.

Fortunately, the more common tumours are typically benign and surgical excision represents the possibility of a curative result ${ }^{10}$. Surgical outcomes have generally been quite positive, with multiple studies quoting gross total resection rates approaching $100 \%$ with minimal morbidity and mortality regardless of histologic subtype ${ }^{11,12}$.

\section{Materials \& Methods:}

The 86 patients with spinal tumour underwent surgery by our team in 7 years (2011-2018) were reviewed retrospectively.

\section{Distribution of the patients:}

\begin{tabular}{ll}
\hline Extradural (ED) & 28 \\
Intradural extramedullary (IDEM) & 46 \\
Intramedullary (IM) & 12 \\
\hline
\end{tabular}

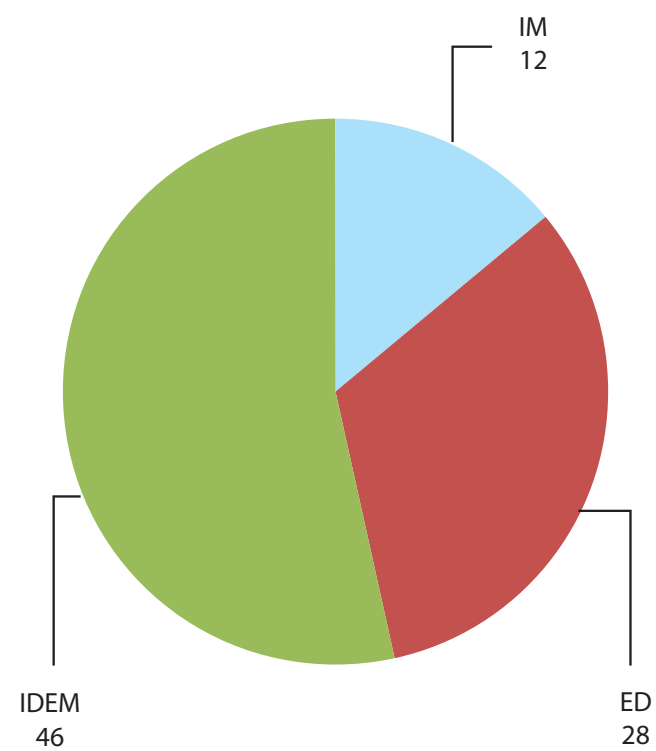

Fig.-1: Pie chart of distribution of patients.
Tablle-I

Characteristics of patients

\begin{tabular}{lc}
\hline Variable & Number $(\%)$ \\
\hline Age & \\
$<20$ & $5(5.81 \%)$ \\
$21-40$ & $27(31.39 \%)$ \\
$41-60$ & $41(47.67 \%)$ \\
$61-80$ & $13(15.11 \%)$
\end{tabular}

Sex

Male

$44(51.16 \%)$

Female

$42(48.83 \%)$

Presenting Symptom

Pain

$86(100 \%)$

Numbness

$64(74.41 \%)$

Paraparesis

$28(32.55 \%)$

Paraplegia

$15(17.44 \%)$

Quadriparesis

$8(9.30 \%)$

Cauda equine syndrome

$3(3.48 \%)$

Neuro-imaging

Plain X-ray

$86(100 \%)$

CT scan

$8(9.30 \%)$

MRI

$86(100 \%)$

Co-morbidity

Hypertension

$58(67.44 \%)$

Diabetes

$27(31.39 \%)$

COPD

$13(15.11 \%)$

Heart failure

$3(3.48 \%)$

Lung Carcinoma

$3(3.48 \%)$

Breast carcinoma

$2(2.32 \%)$

Thyroid gland carcinoma

$1(1.16 \%)$

Bowel adenocarcinoma

$1(1.16 \%)$

The aim of surgery was decompression of the spinal cord, total removal of the tumour when possible and spinal stabilization when needed. Most of the cases were done by laminectomy or laminoplasty.

\section{Results:}

Many factors have influenced the outcome of surgical treatment. The most important are the histological characteristics of tumour, spinal segment affected and the degree of decompression. 
Table-II

Segment involved \& nature of tumour

\begin{tabular}{lc}
\hline Trait & Number $(\%)$ \\
\hline Spinal level & \\
Cervicomedullary Junction & $7(8.13 \%)$ \\
Cervical & $19(22.09 \%)$ \\
Cervico-dorsal junction & $18(20.93 \%)$ \\
Dorsal spine & $35(40.69 \%)$ \\
Conus level & $7(8.13 \%)$ \\
Nature & \\
Metastasis & \\
Meningioma & $20(23.25 \%)$ \\
Schwannoma & $17(19.76 \%)$ \\
Neurofibroma & $16(18.60 \%)$ \\
Ependymoma & $10(11.62 \%)$ \\
Sarcoma & $6(6.97 \%)$ \\
Astrocytoma & $3(3.48 \%)$ \\
Lipoma & $2(2.32 \%)$ \\
Multiple Myeloma & $2(2.32 \%)$ \\
Lymphoma & $2(2.32 \%)$ \\
V. Haemangioma & $1(1.16 \%)$ \\
Haemangioblastoma & $1(1.16 \%)$ \\
Cavernoma & $1(1.16 \%)$ \\
Arachnoid Cyst & $1(1.16 \%)$ \\
\hline
\end{tabular}
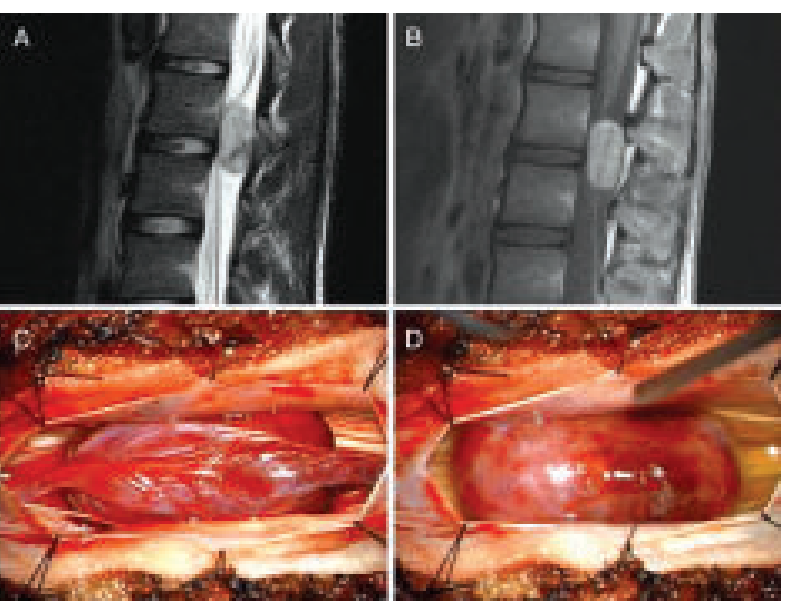

Fig.-2: Intrdural Extramedullary (IDEM) Spinal Tumour

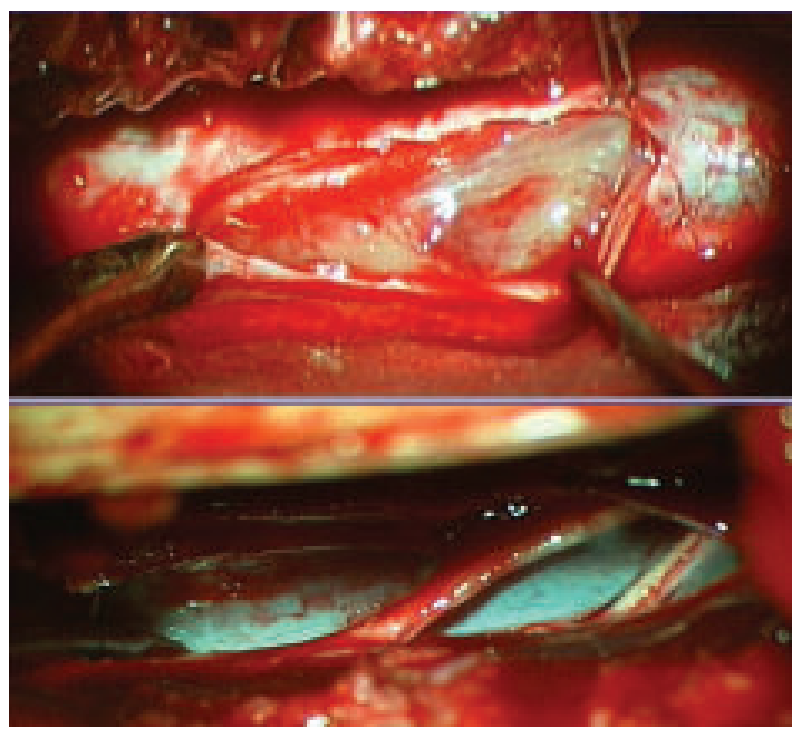

Fig.-3: Intramedullary Spinal Cord Tumour (IMSCT)

Satisfactory postoperative outcome corresponds with the degree of decompression (e.g. total removal of meningioma or neurofibroma leads to full recovery), but decompression in cases of primary intramedullary tumours and metastases were not always satisfactory.

Extent of tumour resection:

Table-III

Surgical resection

\begin{tabular}{lc}
\hline Trait & Number $(\%)$ \\
\hline Gross total & $60(69.76 \%)$ \\
Near total & $16(18.60 \%)$ \\
Subtotal & $7(8.14 \%)$ \\
Biopsy only & $3(3.49 \%)$ \\
\hline
\end{tabular}

Table-IV

Clinical improvement

\begin{tabular}{lc}
\hline Trait & Number (\%) \\
\hline Immediate improvement & $21(24.42 \%)$ \\
Improvement at discharge (7 days) & $29(33.72 \%)$ \\
Improvement at first month follow-up & $12(13.95 \%)$ \\
No improvement & $3(3.48 \%)$ \\
Deterioration & $7(8.13 \%)$ \\
Death & $2(2.33 \%)$ \\
\hline
\end{tabular}

The most frequent difficulties encountered during surgery were the per operative bleeding, anesthetic hazard in previously pulmonary compromised patient, difficulties when undergoing spinal instrumentation due to tumour infiltration etc. 
Table-V

Postoperative complications include

\begin{tabular}{lc}
\hline Complication & Number $(\%)$ \\
\hline CSF leakage & $3(3.48 \%)$ \\
Wound infection & $3(3.48 \%)$ \\
Pseudo-meningocele & $1(1.16 \%)$ \\
Stabilization failure & $2(2.33 \%)$ \\
Deformity & $1(1.16 \%)$ \\
Pneumonia & $1(1.16 \%)$ \\
\hline
\end{tabular}

\section{Discussion:}

The optimal surgical approach provides maximal exposure with the least manipulation of the neural elements. For most intradural extramedullary tumours, resection can be accomplished with a dorsal midline approach. As a general rule, lesions dorsal to the spinal cord can be reached easily using a dorsal midline approach, whereas lesions ventral and lateral to the spinal cord may require resection to provide the best trajectory to the tumour ${ }^{13}$.

In our study, the most of the patients were male $(51.16 \%)$ and belong to the age group of $41-60$ years $(47.67 \%)$. Similar scenario regarding age and sex was reported in Islam MR et al ${ }^{2}$.

The respondents of our study presented with variable types of symptoms, among which pain contributes as $100 \%$ and numbness as $74.41 \%$. In our study 35 cases were at dorsal spine involvement which was highest in location (40.69\%). Regarding nature of tumour the most frequent cases were metastasis $(23.25 \%)$ followed by meningioma $(19.76 \%)$, Schwannoma (18.60\%) and neurofibroma (11.62\%).

The extent of tumour resection and decompression correlates directly with a good outcome. The extent of excision either incomplete or biopsy was found to positively correlate with postoperative improvement. In our study 60 cases $(69.76 \%)$ were underwent operation with gross total removal of tumour, 16 cases $(18.60 \%)$ were underwent operation with near-total removal of tumour, 7 cases $(8.14 \%$ ) were underwent operation with sub-total resection of tumour and in case of rest 3 cases (3.49\%) only biopsy were taken.

In our study 29 patients (33.72\%) were discharged at $7^{\text {th }}$ post-operative day with significant improvement. In 21 patients $(24.42 \%)$ of our study, immediate post- operative improvement were observed. There was no post-operative improvement in 3 cases $(4.48 \%)$, deterioration in 7 cases $(8.13 \%)$ and 2 patients died $(2.32 \%)$ due to severe post-operative complications.

Postoperative complications vary $10-52 \%{ }^{14-29}$. In our study there were different type of post-operative complication like CSF leakage in 3 cases $(3.48 \%)$, wound infection in 3 cases $(3.48 \%)$, pseudomeningocele in 1 case $(1.16 \%)$, stabilization failure in 2 cases $(2.33 \%)$, deformity in 1 case $(1.16 \%)$ and pneumonia in 1 case $(1.16 \%)$.

\section{Conclusion:}

To bring good surgical outcome, to reduce postoperative mortality and peri-operative morbidity in case of spinal tumours, each neurosurgeon has to perform meticulous anatomical dissection mandatorily.

Besides this, thorough perioperative planning, meticulous microsurgical techniques and early mobilization \& rehabilitation are essential for good clinical outcome ${ }^{30}$.

CSF leak and pseudomeningocele formation may be prevented with meticulous dural closure, fat grafting for obliteration of the dead space and 48 hours postoperative bed rest. Patients tend to completely recover their preoperative neurologic deficits even in the case of longstanding preoperative neurological deficit.

\section{References:}

1. T.Avramov, G. Kyuchukov, I. Kiryakov, N. Obreshkov, D. Handjiev, R. Nedelko Clinic of Neurosurgery and Neurology, St. Anna Hospital, Varna Department of Neurosurgery, Eye diseases and ENT, Medical University "Prof. P. Stoyanov", Varna, Bulgaria: Results of Spinal Tumours Surgery: Journal of IMAB - Annual Proceeding (Scientific Papers) 2009, book 1.

2. Islam MR, Siddique MSA, Ahmed M, Khan AS, Afreen S, Das S , Sarker AC:Spinal Tumour Surgery 6 Month Follow up in 34 Cases: Bang. J Neurosurgery 2014; 3(2): 46-50.

3. Cavalcanti DD, Martirosyan NL, Verma K, et al. Surgical management and outcome of schwannomas in the craniocervical region. J Neurosurg.2011;114:1257-1267.

4. Hori T, Takakura K, Sano K: Spinal neurinomas-clinical analysis of 45 surgical cases. Neurol Med Chir 24:471-477, 1984

5. Iraci G, Peserico L, Salar G: Intraspinal neurinomas and meningiomas.A clinical survey of 172 cases. Int Surg 56:289303,1971

6. Levy WJ, Latchaw J, Hahn JF, et al: Spinal neurofibromas: a report of 66 cases and a comparison with meningiomas. Neurosurgery 18:331-334, 1986. 
7. Salah S, Horcajada J, Perneczky A: Spinal neurinomas. A comprehensive clinical and statistical study on 47 cases. Neurochirurgia 18:77-84, 1975

8. Matti T. Seppälä, M.D., Matti J. J. Haltia, M.D., Risto J. Sankila, M.D., Juha E. Jääskeläinen, M.D., and Olli Heiskanen, M.D. Long-term outcome after removal of spinal schwannoma: a clinicopathological study of 187 cases.J Neurosurg 83:621-626, 1995.

9. Klekamp J, Samii M. Surgery of Spinal Tumours. Berlin: Springer, 2007.

10. Aghayev K, Vrionis F, Chamberlain MC. Adult intradural primary spinal cord tumours. J Natl Compr Canc Netw. 9: 434-447, 2011.

11. Albanese V, Platania N. Spinal intradural extramedullary tumours.Personal experience. J Neurosurg Sci. 46: 18-24, 2002.

12. Riad H, Knafo S, Segnarbieux F, Lonjon N. Spinal meningiomas:surgical outcome and literature review. Neurochirurgie. 59: 30-34,2013

13. Gezen F, Kahraman S, Canakci Z, et al. Review of 36 cases of spinal cord meningioma. Spine (Phila Pa 1976). 200;25:727-731.

14. CahillDW, Kumar R: Palliative subtotal vertebrectomy with anterior and posterior reconstruction via a single posterior approach.J Neurosurg 1999, 90: 42-47.

15. Cooper P, Errico T, Martin R et al: A systematic approach to spinal reconstruction after anterior decompression for neoplastic disease of the thoracic and lumbar spine.Neurosurgery 1993, 32: 18(Medline)

16. Gilbert RW, Kim JH, Posner JB: Epidural spinal cord compression from metastatic tumour: diagnosis and treatment. Ann Neurol 1978, 3: 40-51 (Medline)

17. Han IH, Kuh SU, Chin DK, Jin BH, Cho YE: Surgical treatment of primary spinal tumours in the medullaris. J Kor Neurosurg Ass, 2008, 44(2): 72-77
18. Hufana V, Tan JSH, Tan KK: Microsurgical treatment for spinal tumours. Surg Med J, 2005, 46(2):74-77

19. Klekamp J, Samii H: Surgical results for spinal metastases.

20. Acta Neurochir (Wien) 1998, 140: 957967(Medline)

21. Klimo P Jr, Kestle JR, Schmidt MH: Treatment of metastatic spinal epidural disease: a review of the literature.Neurosurg Focus, 2003, 15(5): 1-9

22. Maranzano E, Latini P: Effectiveness of radiation therapywithout surgery in metastatic spinal cord compression:final results from a prospective trial.Int J Radiat Oncol BiolPhys 1995, 32: 959-967(Medline)

23. McCormick PC, Stein BM: Spinalcord tumours in adults. In Youmans JR, ed Neurological Surgery. Philadelphia. WB Saunders, 1998, 3102-3122

24. Schwartz TH, McCormick PC : Intramedullary spinal cord tumours.Special issue. J Neurooncol 2000, 47: 187-317

25. Schwartz TH, McCormick PC : Intramedullary ependymomas: Clinical presentation, surgical treatment, strategies and prognosis. J Neurooncol 2000, 47:211218

26. Sciubba DM, Petteys RJ, GarcesAmbrossi GL, Noggle JC, McGirt MJ et al: Diagnosis and management of sacral tumours. J Neurosurg: Spine ,2009, 10(3) : 244-256

27. Solero CL, Formari M, Giombini S, Lasio G, Oliveri G, Cimino $\mathrm{C}$ et al: Spinal meningeomas: review of 174 operated cases.Neurosurgery 1989, 25: 153-160

28. Sundaresan N, Digiacinto GV, Hughes JE et al: Treatment of neoplastic spinal cord compression: results of prospective study. Neurosurgery 1991, 29: 645-650

29. Sundaresan N, Steinberger AA, Moore F et al : Indications and results of combined anterior-posterior approaches for spine tumour surgery.J Neurosurg 1996, 85:438-446.

30. Kenan Arnautovic, Aska Arnautovic: Extramedullary Intradural Spinal Tumours: A Review Of Modern Diagnostic And Treatment Options and A Report of z Series, Bosnian Journal of Basic Medical Sciences 2009; 9 (supplement 1): S40S45. 